\title{
Comprehensive environmental evaluation of an urbanized territory (using the example of Zavodoukovsk city, Russia)
}

\author{
Marina Podkovyrova ${ }^{1, *}$, Olga Volobueva $^{2}$, and Larisa Gilyova ${ }^{3}$ \\ ${ }^{1}$ Industrial University of Tyumen, Tyumen, Russia
}

\begin{abstract}
The article presents the technique and the result of a comprehensive evaluation of urban land use, ensuring the receipt of complete and reliable information about the urban development, socio-economic and environmental conditions of urban land resources that allows forming the maximum possible sustainable development of the city for the future.
\end{abstract}

\section{Introduction}

Cities, by virtue of their planning structure, have a great influence on the degree of preservation of its original natural spatial and spatial-temporal structures. Thus, the comfort of living of people, as well as the rational use of natural and artificial systems, largely depends on the planning structure of the city. Having a large inertia in contrast to the functional structure, planning structure is difficult to change, thereby preserving the individual characteristics of each city primarily due to the planning framework. Planning framework is characterized by stability over time. It is the planning framework that determines the direction of the territorial development of the city. However, taking into account the fact that the planning framework is based strictly on the transport system of the city, it would be fair to agree with the more exact concept as a "transport-planning framework" [2, 4, 8].

At the same time, the city planning framework, according to our research, is harmoniously or non-harmoniously is included in the environmental (green) framework of the urbanized territory, which has been called the "supporting environmental framework" in scientific literature [2, 4-6]. It follows that all city planning solutions must find a point of contact with the original, historically established level of development of the object under study, thereby forming a sustainable development of the city's territory.

\section{Comprehensive evaluation}

\footnotetext{
*Corresponding author: podkovyrova@mail.ru
} 


\subsection{Methodological basis}

How much urban planning solutions are implemented is determined by the urban planning, socio-economic and environmental assessment in the comprehensive evaluation of the city. The technique of comprehensive assessment proposed in this article is aimed at determining the degree of favorableness of urban areas to a specific type of use: housing development, recreational activities, etc., that allows us to apply a differentiated approach to urban planning and development of urbanized areas of sustainable development [1-3, 5, 8].

In a city planning assessment, a system of evaluation factors and indicators is established, which determines the urban development value of an urban area. The result of urban planning assessment is:

1. Thematic zoning: urban planning; its factor value; favorability with respect to the targeted use of land resources;

2. Identification of drawbacks in the current urban development and use of the city.

3. Development of a city planning vision for development planning and organization of the use of an urban area.

Thus, the urban planning assessment is intended to reveal the nature of city-planning, city-forming and city-serving conditions, to determine the prospects for urban planning development of the territory of the settlement, taking into account a number of factors of environmental, social, economic, historical, architectural, aesthetic and landscape content, which ultimately will represent the result of a comprehensive assessment. It is proposed to use the following factors as a city planning assessment: structure and characteristics of territorial zones (subzones); the level of existing functional relationships; the level of technological development and environmental impact on the urban landscape; intensity of use of the territory.

In order to determine the degree of intensity of use of urban areas, the following indicators are used: territory balance (by territorial zones and functional use); population density; availability and characteristics of the housing stock; housing density; residential security; building density; weighted average number of floors; density of areas occupied by cultural and community facilities; street network density; amount of green areas; level of recreational load; composition and structure of the city land; the level of provision of the city with engineering equipment (their presence, condition, density) [3, 5]. The value of indicators of this type of assessment allows within the boundaries of the city and beyond its borders to determine areas with a strong, medium and low degree of intensity of use and outline options for further urban planning activities, including engineering development.

The following approaches provide the methodological basis for landscape and environmental assessment:

- landscape approach allows you to study the interaction of natural and anthropogenic subsystems in the general system of the city, as well as to determine the external interactions, thereby emphasizing the peculiarity and uniqueness of the estimated object;

- system approach ensures the establishment of cause-effect relationships in the whole chain of interaction between subsystems, determining the significance of each of them;

- predictive approach provides a vision: the total negative impact on the natural territorial complex; prevention of degradation processes; reduction of anthropogenic loads; the preservation of the natural environment (natural landscapes or their elements) and the further use of land in human settlements.

Landscape and environmental assessment of the territory includes the formation of a system of factors (indicators) and indicators characterizing the degree of sustainable development: waste and their location, the quality of water, air and acoustic environment; the presence of protected areas, recreational areas, green spaces and their characteristics; restrictions and encumbrances on land use rights; manifestations of negative physiographic and anthropogenic processes [3-5, 8-10]. 
The main goal of the social and economic assessment of the city is to establish the nature and level of the city's potential in the process of its formation and development, to determine the level of the city's development as a single territorial and residential complex, to resolve the contradictions between maintaining a favorable natural environment and ensuring economic well-being to the city [5].

\subsection{Estimated areas}

We have adopted the city of Zavodoukovsk, Russia, as the object of evaluation. When analyzing the functional organization of its territory, a diffuse and mosaic pattern of its landscape was established, characterizing the features of organizing the use of urban land, as well as the functioning of all its city-planning and city-forming components (Fig. 1).

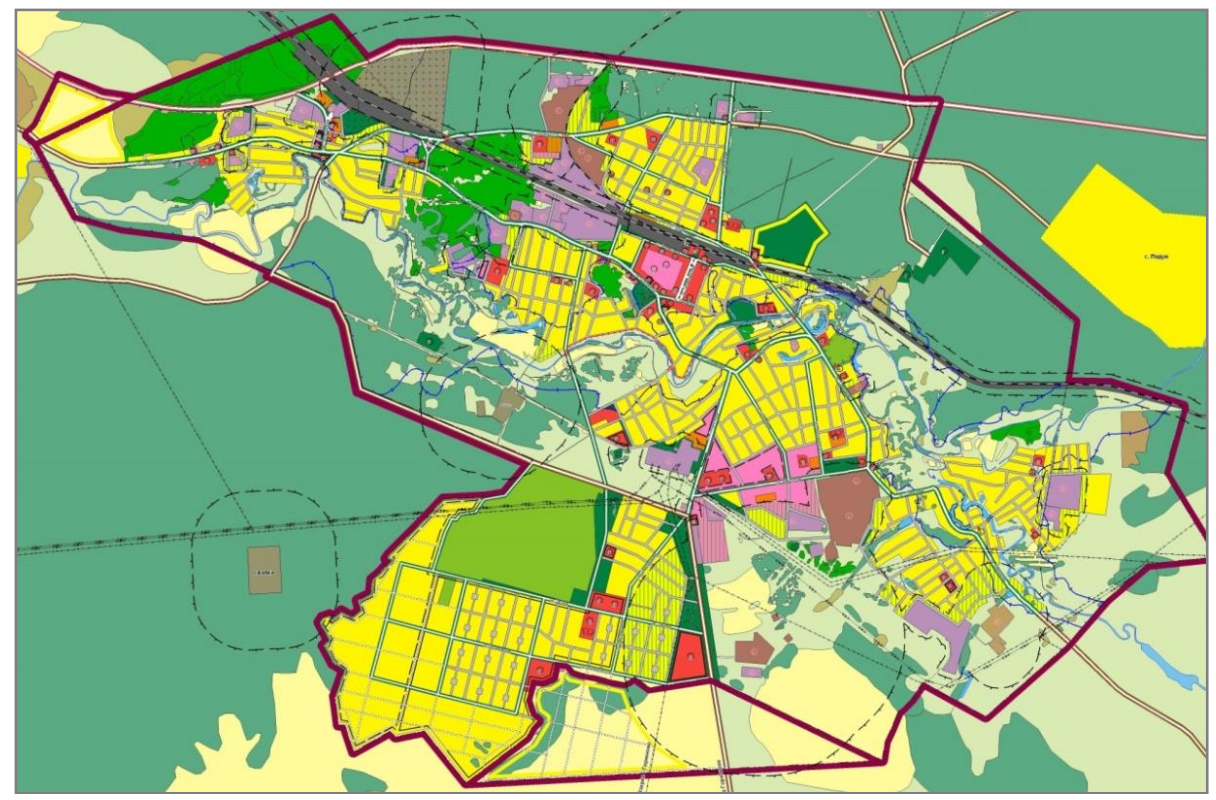

Fig. 1. Diffuse and mosaic pattern of the urban landscape (General plan of the city).

The population density of the city is 383 people per one hectare, which meets sanitary and hygienic requirements; the density of the housing stock is $13,220 \mathrm{~m}^{2} / \mathrm{ha}$; multi-storey building density is $24 \%$, which meets the requirements of Russian building regulations SNiP 2.07.01 - 89*. The density of the road network is $15 \%$, but the road surface needs repairing.

When conducting a comprehensive evaluation of Zavodoukovsk, we considered three estimated areas in more detail (Fig. 2-4); as estimated factors, it is proposed to use the level of negative technological and anthropogenic impact on residential areas, recreational areas, educational, cultural and health facilities, the proportion of dilapidated housing, the level of transportation services for residential areas, the level of provision of estimated areas with educational institutions. For each estimated area, the results of socio-economic assessment are presented in tabular form.

\subsubsection{Estimated area No 1 (Districts DSU and Selozavod)}

Table 1. The value of the estimated factors for the estimated area No 1 . 


\begin{tabular}{|c|c|c|c|}
\hline \multirow{2}{*}{$\begin{array}{c}\text { Object of negative } \\
\text { impact }\end{array}$} & \multicolumn{3}{|c|}{ Impact Indicators, \% } \\
\hline & Residential area & Recreation area & $\begin{array}{c}\text { Public and business } \\
\text { area }\end{array}$ \\
\hline Recycling (cemetery) & $\begin{array}{l}10 \text { (residential estate } \\
\text { development) }\end{array}$ & 12.5 & - \\
\hline Industry & $\begin{array}{c}8 \text { (residential estate } \\
\text { development) }\end{array}$ & 0.3 & - \\
\hline Railway transport & $\begin{array}{c}0.5 \text { (residential estate } \\
\text { development) }\end{array}$ & 1.7 & - \\
\hline
\end{tabular}

\section{Conclusions:}

1. The presence of dilapidated housing in this estimated area is $21.0 \%$. When analyzing the proposed demolition and construction of new housing, an assessment was made of the urban area regarding its degree of favorableness for urban development on the basis of the environmental conditions and the development of the elements of the transport framework. The most favorable territory is the south-western part of the estimated area No 1.

2. The level of recreational support is equal to $27.0 \%$. Regarding the landscape design, all recreational plots are located in the northern and southern parts of the estimated area, therefore, it is proposed to carry out a set of works on landscaping urban areas subject to demolition of dilapidated housing (Table 1).

3. The level of transport accessibility is determined by calculating the relative indicator $\left(\mathrm{K}_{\mathrm{t} . \mathrm{d} .}\right)$, the value of which is equal to 0.8 , which indicates the development of the road network and the perfection of its road surface.

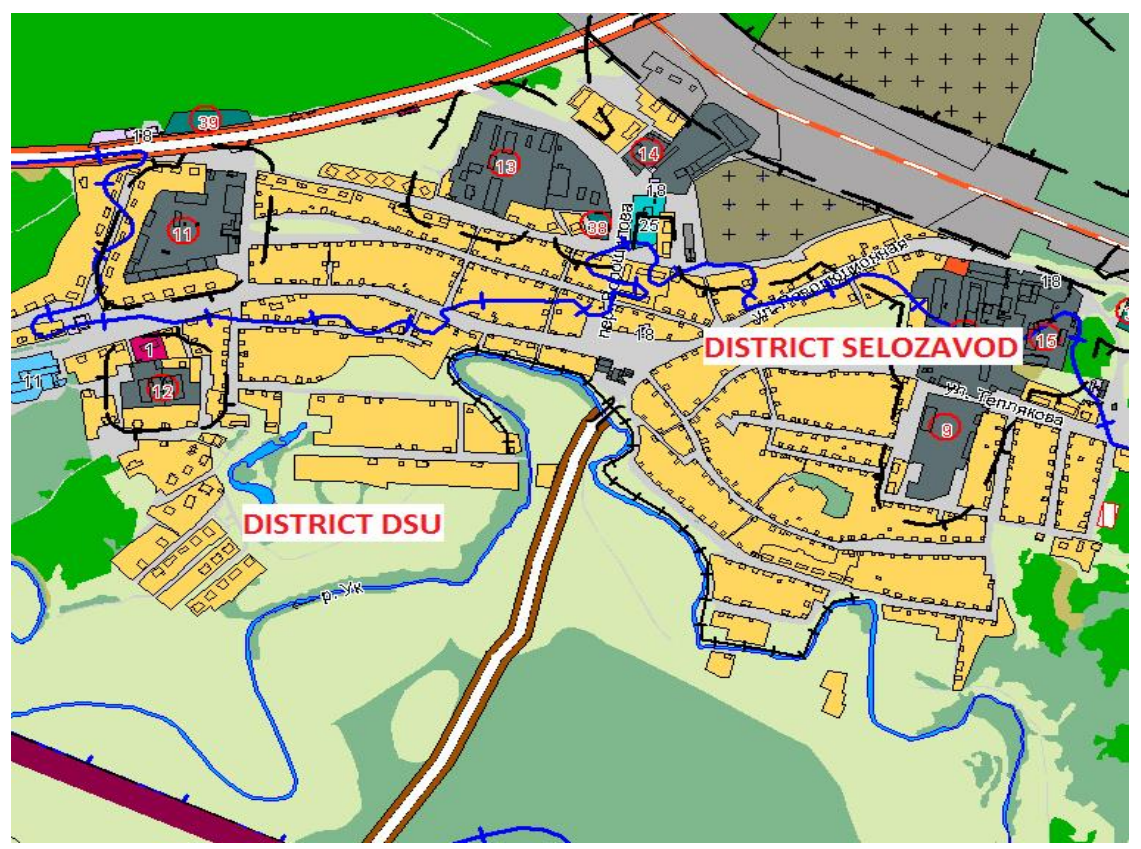

Fig. 2. Estimated area No 1 (Districts DSU and Selozavod).

\subsubsection{Estimated area No 2 (District Zalinia)}

The result of assessment: 
1. The presence of dilapidated housing is $10.2 \%$. It is offered to execute demolition of shabby housing and to plan new construction on the favorable (with respect to the environmental situation, development of the elements of the transport frame) southern and southwestern part of the estimated area No. 2 is proposed.

2. The level of recreational support for residents is $52.0 \%$. Regarding the landscape design, all recreational plots are located in the northern and southern parts of the estimated area, in this connection, it is proposed to improve green infrastructure in urban areas included in the zone of dilapidated housing (Table 3).

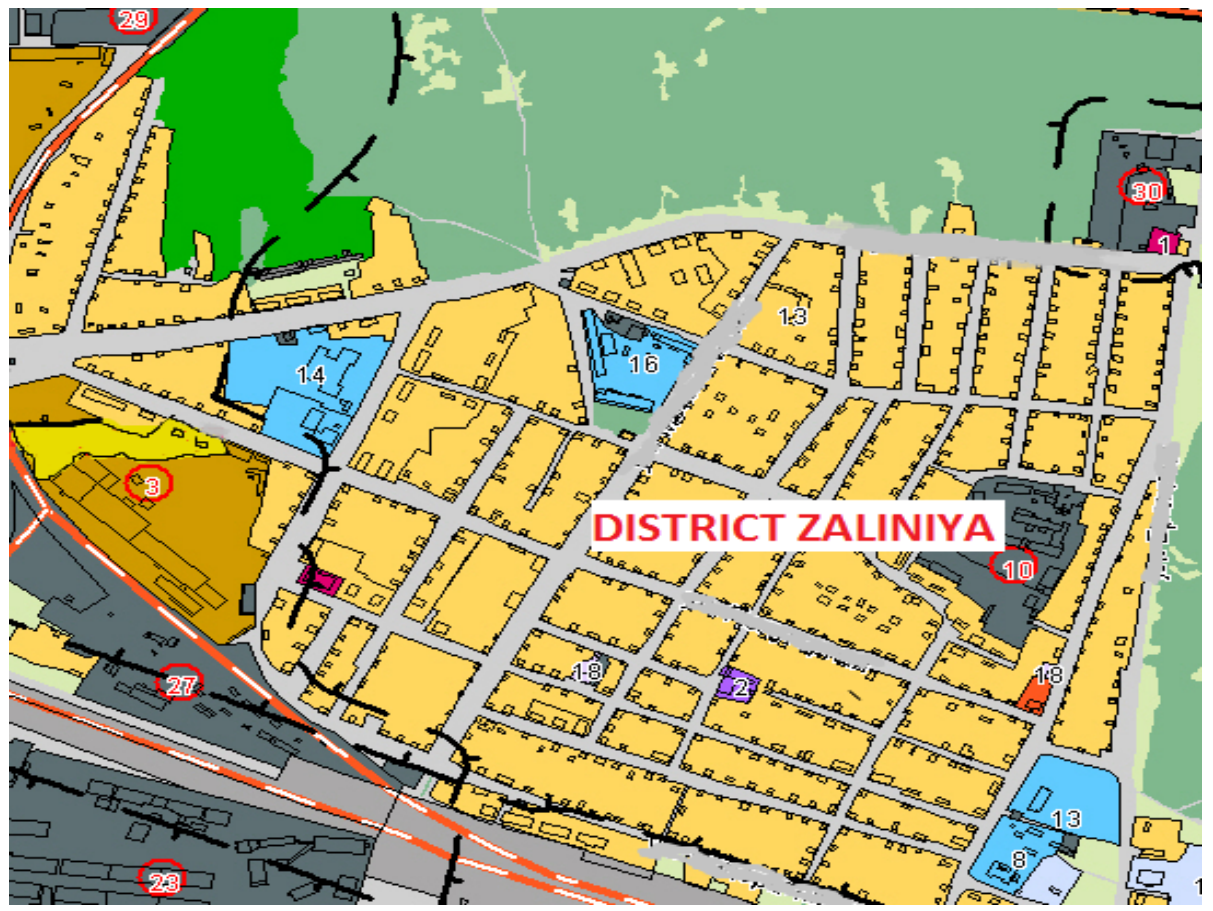

Fig. 3. Estimated area No 2 (District Zalinia).

Table 3. The value of the estimated factors for the estimated area No. 2.

\begin{tabular}{|c|c|c|c|}
\hline Object of negative impact & \multicolumn{3}{|c|}{ Impact Indicators, \% } \\
\cline { 2 - 4 } & Residential area & Recreation area & $\begin{array}{c}\text { Public and } \\
\text { business area }\end{array}$ \\
\hline Recycling (cemetery) & 11 & 12.5 & - \\
\hline Industry & 12.8 & 0.3 & 0.3 \\
\hline Railway transport & 13.5 & 1.7 & - \\
\hline
\end{tabular}

Conclusions:

The level of transport accessibility of public and cultural facilities is determined for educational institutions:

$-54.0 \%$ of the residential study area is not provided with kindergartens;

$-32.0 \%$ of the residential study area is not provided with schools.

Results of assessment confirm need of construction of facilities of preschool institutions and schools.

\subsubsection{Estimated area No 3 (District Center)}


Table 4. The value of the estimated factors for the estimated area No. 3 .

\begin{tabular}{|c|c|c|c|}
\hline \multirow{2}{*}{ Object of negative impact } & \multicolumn{3}{|c|}{ Impact Indicators, \% } \\
\cline { 2 - 4 } & Residential area & Recreation area & $\begin{array}{c}\text { Public and business } \\
\text { area }\end{array}$ \\
\hline Recycling (cemetery) & - & - & - \\
\hline Industry & 0.6 & 2.1 & 0.01 \\
\hline Railway transport & 0.07 & 0.01 & - \\
\hline
\end{tabular}

Conclusions:

1. The presence of dilapidated housing is $31.0 \%$, which requires its demolition and planning of new construction in an environmentally friendly environment, as well as the development of elements of the transport frame of the urban area (southern and southwestern parts of the central estimated area No. 3).

2. The level of recreational support is $28.7 \%$. Regarding the landscape design, all recreational plots are located in the western and southern parts of the estimated area, in this connection it is proposed to improve green infrastructure in urban areas included in the zone of dilapidated housing (Table 4). The level of transport accessibility is 0.67 , which indicates the high level of development of the road network and the perfection of the road surface.

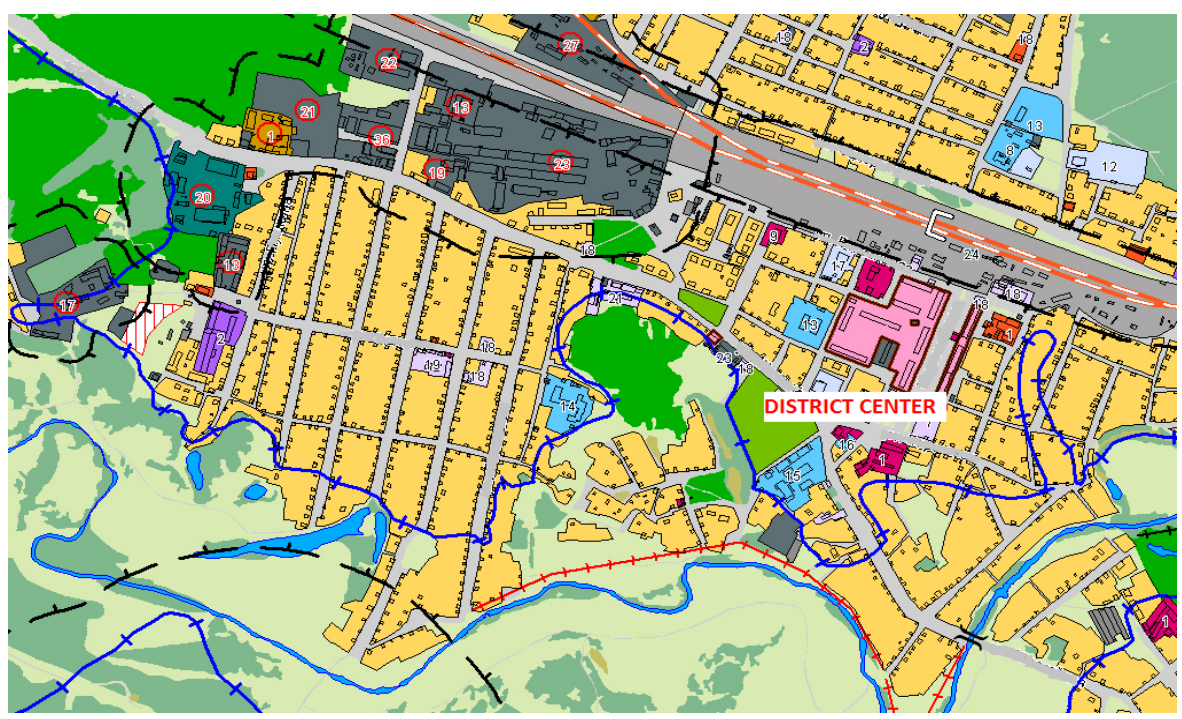

Fig. 4. Estimated area No 3 (District Center).

When making an environmental evaluation of the territory of Zavodoukovsk: landscape and environmental zoning of the city territory was performed; restrictions and encumbrances on rights to use land plots (urban real property) have been established; the analysis of compliance with land use regimes in each of the landscape and environmental zone established has been carried out; environmental sustainability coefficient has been calculated.

The environmental state of the territory forms the social, city planning conditions for the comfort of the residents, as well as the economic potential of the city. In the studied estimated areas, the coefficient of environmental sustainability was:

1) Estimated area No 1 (Districts DSU and Selozavod) - 0.25.

2) Estimated area No 2 (District Zalinia) - 0.31.

3) Estimated area No 3 (District Center) - 0.37. 
In order to improve the environmental state of the urban environment and living conditions, the municipality allocates funds for the improvement of the city (Table 5).

Table 5. Activities aimed at improving the environment.

\begin{tabular}{|l|c|c|c|c|}
\hline \multicolumn{1}{|c|}{ Name } & \multicolumn{2}{|c|}{ Implemented } & \multicolumn{2}{c|}{ Planned } \\
\cline { 2 - 5 } & 2017 & 2018 & 2019 & 2020 \\
\hline $\begin{array}{l}\text { Budget expenditures for } \\
\text { city improvement } \\
\text { (thousand rubles) }\end{array}$ & 34355 & 36037 & 37787 & 39770 \\
\hline $\begin{array}{l}\text { Including planting of } \\
\text { greenery of territories } \\
\text { and the maintenance of } \\
\text { recreation facilities of }\end{array}$ & 6345 & 6660 & 6995 & 7345 \\
\hline $\begin{array}{l}\text { Maintenance } \\
\text { cemeteries }\end{array}$ & 500 & 600 & 600 & 600 \\
\hline Other city improvements & 10836 & 11378 & 11947 & 12544 \\
\hline Street lighting & 15701 & 16643 & 17642 & 18700 \\
\hline
\end{tabular}

\section{Conclusions}

As a conclusion, it follows that a comprehensive evaluation of the territory of the city of Zavodoukovsk has determined the level of compliance of the use of urban land with their intended purpose. The materials of the results of the comprehensive assessment allowed us to create an information and analytical basis for subsequent adjustments to the territorial planning materials of the city, the activities aimed at improving the environment, thus ensuring their sustainable development.

\section{References}

1. M. Podkovyrova, Land management, cadastral, geodetic works to ensure the stability and efficiency of the development of the Russian economy: Proceedings of the Intern. scient. pract. conf. (Omsk, 2005)

2. Urban Development Code of the Russian Federation (Moscow, 2014)

3. M. Podkovyrova, A. Oleinik, A. Matveeva, E. Ivanenko, Basics of urban planning and planning of populated areas (Tyumen, 2016)

4. G. Lappo, Geography of cities (Moscow, VLADOS, 1997)

5. M. Podkovyrova, Landscape-environmental provisions of the organization of land use of settlements on the basis of a comprehensive assessment (on materials of Omsk and its suburban area) (Omsk, 2005)

6. M. Podkovyrova, I. Podkovyrova, Proceedings of the Intern. scientific. practical. conf., dedicated to the international conservation action "March of Parks 2007" (Kokshetau University, 2007)

7. M. Podkovyrova, A. Oleinik, Scientific and methodological foundations of the functioning of the land and property complex (Tyumen, 2018)

8. M. Podkovyrova, A. Oleinik, Landscape-environmental organization of the territory: monograph (Omsk, 2019)

9. A. Oleinik, M. Podkovyrova, I. Kurashko, L. Gileva, Planning Methodology, Organization of Rational Use and Protection of Land (Tyumen, 2019) 
10. V. Sidorchuk, The development of environmental auditing in the field of environmental management and environmental protection: theory, methods and practice (Moscow, 2002) 